\title{
Variación de las características y epidemiología de los pacientes con neumonía adquirida en la comunidad atendidos en los servicios de urgencias hospitalarios
}

\section{A. Julián-Jiménez ${ }^{1 *}$, J. González del Castillo ${ }^{2}$, M. Martínez Ortíz de Zárate ${ }^{3}$, F.J. Candel González ${ }^{4}$ (en representación del grupo INFURG-SEMES)}

\section{Sr. Director:}

Hemos leído con gran atención la carta de Aguinaga y Belzunegui ${ }^{1}$ en relación con la "Variación de las características y epidemiología de los pacientes con neumonía adquirida en la comunidad atendidos en los servicios de urgencias hospitalarios". Agradecemos sus comentarios y queremos manifestar que estamos de acuerdo en la mayoría de sus acertadas apreciaciones, aunque nos gustaría resaltar algunos aspectos que, a nuestro juicio como médicos del servicio de Urgencias, nos parecen de vital importancia en relación con la atención al paciente con neumonía adquirida en la comunidad (NAC) en los servicios de urgencias (SU). Y que además, a juzgar no solo por nuestros estudios ${ }^{2-4}$, sino también por lo referido por los últimos documentos de consenso o guías de práctica clínica (GPC) multidisciplinares, tanto nacionales ${ }^{5}$ como internacionales ${ }^{6}$, parece que por fin se reconoce y valora tanto el importante impacto que tiene la NAC en los SU $(1,35 \%$ de todos los pacientes atendidos, primera causa de mortalidad por enfermedad infecciosa, primera causa de ingreso en la unidad de cuidados intensivos de origen infeccioso desde el SU, primera causa de

* Autor para la correspondencia

1. Servicio de Urgencias. Complejo Hospitalario de Toledo. Toledo. España.

2. Servicio de Urgencias. Hospital Universitario Clínico San Carlos. Madrid. España. sepsis grave y shock séptico en los $\mathrm{SU}$, segunda causa de bacteriemia aislada procedente de los SU y primera causa de fallecimiento en el SU por proceso infeccioso $)^{2,3}$, como la trascendencia e importancia de las primeras decisiones, muchas empíricas, que debemos tomar los profesionales del servicio de Urgencias y que marcarán el pronóstico, evolución y morbimortalidad de los pacientes con NAC (alta o ingreso, adecuación y precocidad de la administración de la pauta antibiótica, soporte respiratorio y hemodinámico, solicitud de pruebas microbiológicas, etc. $)^{2,4,5}$. En este sentido coincidimos plenamente con los autores en la importancia, y necesidad, de poner en marcha el llamado "Código NAC" que en definitiva no sería más que una guía adaptada y consensuada con el resto de especialistas con el objetivo de detectar y tratar lo más precoz y adecuadamente al paciente con NAC en el SU, sobre todo en los casos más graves, cuya utilidad, eficacia y eficiencia han sido demostradas en recientes trabajos ${ }^{4}$. En este sentido, como apuntan los autores, tanto la precocidad como la adecuación de la pauta antimicrobiana se han mostrado como dos de los factores más relacionados con la mortalidad tanto intrahospitalaria como a los 30

3. Servicio de Urgencias. Hospital Universitario de Basurto. Bilbao. España.

4. Servicio de Microbiología Clínica. Hospital Universitario Clínico San Carlos. Madrid. España. 
días en los pacientes con NAC. Aunque en la actualidad es un aspecto controvertido y las últimas guías recomiendan que la administración precoz se optimice en los pacientes graves y en aquellos donde ya se haya confirmado el diagnóstico de NAC en el $\mathrm{SU}^{5,6}$, en un reciente estudio se ha confirmado cómo la mortalidad disminuye con la precocidad de la administración del antimicrobiano una vez establecido el diagnóstico de NAC (mortalidad intrahospitalaria $21,3 \%$ frente a $7,5 \%, \mathrm{p}<0,001 \mathrm{y}$ mortalidad a los 30 días $15 \%$ frente a $7,9 \%$, $\mathrm{p}=0,003)$ y con la adecuación de la pauta antimicrobiana (mortalidad intrahospitalaria $34,5 \%$ frente a $5,9 \%, \mathrm{p}<0,001$ y mortalidad a los 30 días $34,5 \%$ frente a $5,9 \%$, $\mathrm{p}<0,001)$ gracias al seguimiento de una $\mathrm{GPC}^{4}$. Pero como también señalan Aguinaga y Belzunegui ${ }^{1}$ no solo el mejorar la atención de la NAC a través de la puesta en marcha de una GPC es posible, sino que debe ser un objetivo prioritario de todos los $\mathrm{SU}^{4-6}$. Con este objetivo desde INFURGSEMES (Grupo de trabajo de infecciones de la Sociedad Española de Medicina de Urgencias y Emergencias) hemos promovido la elaboración de GPC multidisciplinares orientadas a los SU que se puedan adaptar a cada centro y que incluyen herramientas de ayuda que han demostrado su utilidad a la hora de la valoración pronóstica y de la toma de decisiones ${ }^{4}$. En este sentido la incorporación de una escala pronóstica de gravedad (Pneumonia Severity IndexPSI modificado) junto con la valoración de la concentración de procalcitonina (y otros biomarcadores de inflamación e infección $)^{4}$ y el lactato han demostrado recientemente su utilidad y capacidad para predecir mortalidad, gravedad, existencia de bacteriemia asociada a la NAC e incluso orientación diagnóstica, de forma que ayudan a mejorar la adecuación de la decisión de alta o ingreso (disminuyen las altas improcedentes y los ingresos innecesarios) y la administración precoz y adecuada de la pauta antimicrobiana ${ }^{7-9}$. Y todo ello, como también señalan los autores, en el contexto de pacientes con mayor dificultad diagnóstica al presentar mayor edad, mayor frecuencia de comorbilidades asociadas y de factores de riesgo para presentar patógenos multirresistentes e inmunodeprimidos con menor respuesta inflamatoria en los que el diagnóstico de NAC y de sepsis se retrasa $\mathrm{a}^{2,3,10}$. Precisamente, como se preguntan los autores, la adecuación de las altas e ingresos no han sido analizadas en nuestro estudio, aunque existen trabajos recientes que confirman que en el $35 \%$ de los pacientes la decisión de alta o ingreso no se corresponde con su valoración pronóstica y este porcentaje se reduce de forma significativa, y por tanto se mejora la eficacia y eficiencia, al 2,5\% al utilizar una GPC que incluye el PSI modificado y la determinación de procalcitonina y lactato ${ }^{4,9}$. Por otro lado es cierto que algunas de las características epidemiológicas y algunos datos no se han incorporado por las limitaciones de espacio en nuestro estudio, al contrario de lo que sí han hecho otros estudios unicéntricos ${ }^{4}$. Por ejemplo, no se ha cuantificado con qué frecuencia el paciente acude por iniciativa propia o es derivado por su médico de atención primaria, y por lo tanto no se ha podido analizar la adecuación de la derivación (como tampoco se ha estudiado la de la pauta prescrita). Aunque estamos de acuerdo en que éste es un factor muy importante para conocer las características epidemiológicas de los pacientes con NAC que atendemos en los SU. Por ello, en la actualidad, lo estamos analizando en otro estudio que está en proceso. Por otro lado es cierto que la neumonía relacionada con cuidados sociosanitarios se ha convertido en los últimos años en una "entidad propia y diferenciada" en las recomendaciones de los expertos, sin embargo y tal como se decidió en la "guía multidisciplinar para la valoración pronóstica, diagnóstico y tratamiento de la neumonía adquirida en la comunidad"5, donde participó INFURG-SEMES, se decidió clasificar los grupos de pacientes con NAC más que por su procedencia (institucionalizados el $10,2 \%)^{2}$ por la existencia de factores de riesgo de posibles patógenos multirresistentes (que presentarían el $17,8 \%)^{2}$ y que sería el factor clave para decidir una atención y tratamiento diferen$\mathrm{te}^{5}$. Finalmente, y al hilo de lo comentado 
por los autores, resulta fundamental seguir aunando esfuerzos para mejorar la atención de los pacientes con NAC en los SU a través de GPC adaptables a las distintas características de cada SU, pero sin renunciar a las herramientas de ayuda que estén disponibles para la valoración pronóstica y la toma de decisiones diagnóstico-terapéuticas. La evolución y el pronóstico de nuestros pacientes están en juego, lo que no pude ser cuestionable.

\section{BIBLIOGRAFÍA}

1. Santiago Aguinaga I, Belzunegui Otano T. Variación de las características y epidemiología de los pacientes con neumonía adquirida en la comunidad atendidos en los servicios de urgencias hospitalarios. An Sist Sanit Navar 2014; 37

2. Julián-JimÉnez A, González del Castillo J, Martínez Ortiz de Zárate M, Candel González FJ, Piñera SALMERÓN P, MoYA MIR MS (en representación del grupo INFURG-SEMES). Características y cambios epidemiológicos de los pacientes con neumonía adquirida en la comunidad en los servicios de urgencias hospitalarios. An Sist Sanit Navar 2013; 36: 387-395.

3. Martínez Ortiz de Zárate M, González del Castillo J, Julián-Jiménez A, Piñera Salmerón P, Llopis Roca F, Guardiola Tey JM et al. Estudio INFURG-SEMES: epidemiología de las infecciones en los servicios de urgencias hospitalarios y evolución durante la última década. Emergencias 2013; 25: 368-378.
4. Julián-Jiménez A, Parejo R, Cuena-Boy R, Palomo MJ, Laín-TerÉs N, Lozano-Ancín A. Intervenciones para mejorar el manejo de la neumonía adquirida en la comunidad desde el servicio de urgencias. Emergencias 2013; 25: 379-392.

5. Torres A, Barberán J, Falgera M, Menéndez R, Molina J, Olaechea $P$ et al. Guía multidisciplinar para la valoración pronóstica, diagnóstico y tratamiento de la neumonía adquirida en la comunidad. Med Clin (Barc) 2013; 140: 223.e1-223.e19.

6. WUNDERINK RG, Waterer GW. CommunityAcquired Pneumonia. N Engl J Med 2014; 370 : 543-551.

7. JULIÁN-JimÉNEZ A. Biomarcadores de infección en urgencias: ¿cuáles pueden sernos útiles? Emergencias 2012; 24: 343-345.

8. Tudela P, Prat C, Lacoma A, Mòdol JM, DomínGUEZ J, GimÉNEZ M et al. Biomarcadores para la predicción en urgencias de infección bacteriana, bacteriemia y gravedad. Emergencias 2012; 24; 348-356.

9. Julián-Jiménez A, Timón J, Laserna EJ, SiciliaBravo I, Palomo MJ, Cabezas-Martínez A et al. Poder diagnóstico y pronóstico de los biomarcadores para mejorar el manejo de la neumonía adquirida en la comunidad en los servicios de urgencias. Enferm Infecc Microbiol Clin 2013. http://dx.doi.org/10.1016/j. eimc.2013.04.015.

10. Perelló R, Miró O, Camón S, Sánchez M, Miró JM, Marcos MA et al. Aproximación al valor pronóstico de diferentes marcadores identificables en urgencias en pacientes VIH con neumonía: Valor de la PCR. Emergencias 2013; 25: 268-272. 
